Research Article

\title{
Electrochemical Characterization of Cu-Catalysed Si Nanowires as an Anode for Lithium-Ion Cells
}

\author{
P. P. Prosini, ${ }^{1}$ F. Rondino $\left(\mathrm{D},{ }^{2}\right.$ M. Moreno, ${ }^{1}$ C. Cento, ${ }^{1}$ M. Ottaviani, ${ }^{1,3}$ A. Rufoloni, ${ }^{2}$ \\ L. Pilloni, ${ }^{4}$ V. Orsetti, ${ }^{2}$ and A. Santoni ${ }^{2}$ \\ ${ }^{1}$ Energy Technologies Department, ENEA C.R. Casaccia, Rome, Italy \\ ${ }^{2}$ Fusion and Technologies for Nuclear Safety and Security Department, ENEA C.R. Frascati, Italy \\ ${ }^{3}$ SBAI Department "La Sapienza" University of Rome, Via del Castro Laurenziano 7, Rome, Italy \\ ${ }^{4}$ Territorial and Production Systems Sustainability Department, ENEA C.R. Casaccia, Rome, Italy
}

Correspondence should be addressed to F. Rondino; flaminia.rondino@enea.it

Received 11 April 2020; Revised 24 June 2020; Accepted 6 July 2020; Published 22 July 2020

Guest Editor: Arántzazu González-Campo

Copyright (c) 2020 P. P. Prosini et al. This is an open access article distributed under the Creative Commons Attribution License, which permits unrestricted use, distribution, and reproduction in any medium, provided the original work is properly cited.

Silicon ( $\mathrm{Si}$ ) nanowires (NWs) grown on stainless-steel substrates by Cu-catalysed Chemical Vapour Deposition (CVD) have been prepared to be used as anodes in lithium-ion batteries. The use of NWs can overcome the problems related to the Si volume changes occurring during lithium alloying by reducing stress relaxation and preventing material fragmentation. Moreover, since the SiNWs are grown directly on the substrate, which also acts as a current collector, an excellent electrical contact is generated between the two materials without the necessity to use additional binders or conducting additives. The electrochemical performance of the SiNWs was tested in cells using lithium metal as the anode. A large irreversible capacity was observed during the first cycle and, to a lesser extent, during the second cycle. All the subsequent cycles showed good reversibility even if the coulombic efficiency did not exceed $95 \%$, suggesting the formation of an unstable SEI film and a continuous decomposition of the electrolyte on the silicon surface. The absence of a stable SEI film was assumed responsible for a linear capacity fade observed upon cycling. On the other hand, the electrochemical characterization performed at different values of the charging current showed that SiNWs possess an exceptionally high rate capability.

\section{Introduction}

Rechargeable lithium-ion batteries (LIBs) are considered as one of the most versatile storage systems to power consumer electric devices, electric vehicles, and stationary energy storage systems due to their high energy density, long cycle life, and high-power performance $[1,2]$. However, the development of new and sustainable electrode materials that can increase the energy density of LIB is still an open challenge. State-of-the-art electrode materials for LIBs exhibit a good capacity retention over many cycles but are characterized by a relatively low specific capacity $\left(370 \mathrm{mAhg}^{-1}\right.$ and $180 \mathrm{mAh} \mathrm{g}^{-1}$ for the anode and cathode, respectively), due to the limited number of intercalation sites for $\mathrm{Li}$ ions. In recent years, silicon is emerging as a promising candidate to replace the conventional LIB anode based on graphite, because it offers an impressive specific capacity (up to $3600 \mathrm{mAh} \mathrm{g}^{-1}$ ) and a low delithiation potential (below $0.5 \mathrm{~V}$ against $\left.\mathrm{Li} / \mathrm{Li}^{+}\right)[3,4]$. However, its practical application has some drawbacks such as the poor capacity retention related to the electrode pulverization promoted by the huge volume expansion (up to 400\%) occurring during the charge/discharge cycles [5].

To overcome these disadvantages, great effort has been aimed at the investigation of alternative silicon structures. In this context, silicon nanoparticles [6,7], silicon nanowires/nanotubes [8-10], nanosheets [11-13], nanofilms [14], and $3 \mathrm{D}$ porous structures $[15,16]$ have been intensely studied to improve the anode performance significantly. At the same time, extensive research has been carried out to combine the silicon nanostructures with different carbon materials $[17,18]$ such as amorphous carbon [19], conductive 
carbon black [20], carbon nanotubes [21], and graphene $[22,23]$. The insertion of metal nanoparticles has been also explored in terms of surface modification of the Si nanostructure to improve overall performance, particularly coulombic efficiency and power capability [24, 25]. Furthermore, polymeric coating has been widely investigated due to the evident improvement of the electrical conductivity of the Si-based anode and to the better capability of accepting the volume change during the charge-discharge processes $[26,27]$. As a result, this kind of anode exhibits an excellent long-term cycling ability with capacity retention of $83.4 \%$ over 350 cycles at $0.5 \mathrm{C}$ [28].

Among 1D nanostructures, SiNWs have attracted much attention due to the large specific surface area, short diffusion path, and reduced internal stress and, especially, because they have a high cracking strength that can improve their electrochemical performance in terms of capacity retention [29]. In addition, they can be grown directly on the current collector eliminating the need for binders or conductive materials. Despite these promising properties, SiNWs still suffer from capacity degradation when the number of charge-discharge cycles increases. In addition, SiNW-based anodes show a low first cycle coulombic efficiency (about 70\%), which has been attributed to the decomposition of the electrolyte with the destruction and continuous growth of the SEI layer $[30,31]$. Efficiency increases in subsequent cycles, but the capacity recovered in the charge is always less than that used during the discharge process. This aspect can be related to the enormous increase in volume that silicon undergoes during the lithiation process. Indeed, many studies have demonstrated that the large volume change occurring during lithium insertion induces cracking in the SEI that continuously produces a $\mathrm{Si}$ fresh surface leading to $\mathrm{Li}$ consumption and adding new material able to disrupt the previous SEI layer [32]. Currently, the insertion of various materials into SiNW-based anodes through metal or metal oxide doping has clearly shown to be an efficient strategy for the improvement of the electrochemical performances leading to longterm cycling and an excellent rate performance [33]. Recently, Sadeghipari et al. [34] have demonstrated that the $\mathrm{Al}_{2} \mathrm{O}_{3}$-encapsulated SiNWs can exhibit a high reversible discharge capacity of about $3000 \mathrm{mAh} \mathrm{g}^{-1}$ at a rate of $\mathrm{C} / 16$, and at a higher rate density, this electrode can deliver a high capacity of $965 \mathrm{mAh} \mathrm{g}^{-1}$ with an excellent capacity retention of $94 \%$ over 120 cycles.

On the other hand, a uniform and complete carbon coating of SiNWs was also found to prevent the nanowire expansion needed to exhibit capacities of $2000 \mathrm{mAh} \mathrm{g}^{-1}$ over 300 cycles $[35,36]$.

Unfortunately, despite the evident progress, several drawbacks still limit the SiNW use in LIBs such as low specific energy density, low mass loading, and high processing cost.

Based on these considerations, in this paper, we have investigated the electrochemical properties of $\mathrm{Cu}$-catalysed SiNWs grown directly on a stainless-steel substrate by the Vapour-Liquid-Solid (VLS) mechanism in a Chemical Vapour Deposition (CVD) reactor. The CVD method is widely used to grow SiNWs mainly with Au metal as the catalyst. However, its practical application is limited because of its high cost and its involvement in parasitic reactions causing the decomposition of the electrolyte or of the solvent on the SiNW surface leading to the formation of an unstable SEI layer $[9,37,38]$. Among the alternative catalyst materials, the use of the less expensive, Si-compatible $\mathrm{Cu}$ catalyst could be advantageous for growing SiNWs for LIB applications. Another advance to improve the ability of SiNWs to be used as anodes is the possibility to synthesize crystallineamorphous core-shell nanowires. The electrochemical activity of the amorphous Si shells can be limited by selecting the lithiation potential. In these conditions, the crystalline core acts as a mechanical support and electrical conductor while the amorphous part stores the $\mathrm{Li}$ ions. Indeed, the crystalline-amorphous structure plays a fundamental role in the SiNW technology allowing to obtain high charge storage capacities $(1000 \mathrm{~mA} / \mathrm{g})$ with $90 \%$ capacity retention over 100 cycles [39]. In this work, we report about the CVD synthesis on stainless steel of $\mathrm{Cu}$-catalysed SiNWs with a well-defined morphology and core-shell structure. To evaluate their Li storage properties, the SiNWs were used as electrodes in an electrochemical cell against lithium metal, without using any binder or additive. The electrodes showed a large capacity and maintained a good reversibility for the first ten cycles. On the other hand, long-term cycling was considered unsuitable for practical applications.

\section{Experimental}

2.1. Synthesis of SiNWs. Among the various methods used to synthesize SiNWs [24], the most popular is surely CVD based on the VLS mechanism [40, 41]. According to this process, we have grown SiNWs directly on 304 stainless-steel substrates $\left(10 \times 10 \mathrm{~mm}^{2}, 30 \mu \mathrm{m}\right.$ thick $)$ without using binders or additives. Before the insertion of the substrates into the CVD furnace (Lenton, UK), they were decorated with the $\mathrm{Cu}$ catalyst using a commercial suspension (PlasmaChem) that provides a known density $(6 \mu \mathrm{g} / \mathrm{ml})$ and a known diameter $(40 \mathrm{~nm})$ of the primary copper nanoparticles. In order to obtain a uniform metallic nanoparticle distribution and prevent agglomeration, a modified commercial pneumatic nebulizer for medical use (Chiesi, Clenny A Aerosol) was used. After the functionalization, the decorated substrates were inserted into a 1-inch diameter quartz tube using a ceramic container and placed into the oven.

In order to obtain suitable SiNW electrodes for LIBs, an accurate choice of the growing parameters was performed. In particular, the influence of the temperature on the SiNW growth was investigated. In fact, although the eutectic temperature of the $\mathrm{Cu} / \mathrm{Si}$ alloy required for the SiNW growth by the VLS mechanism is $802^{\circ} \mathrm{C}$, the synthesis of SiNWs can also occur at lower temperatures and may be ascribed to a VSS (Vapour-Solid-Solid) process [42-44]. Based on this consideration, pure silane gas (used as the Si precursor) was introduced at a pressure of around 2 Torr with a flux of $6 \mathrm{sccm}$ for 12 minutes. In order to investigate the role of the temperature on the growth, the temperature was varied from the $500^{\circ} \mathrm{C}$ up to $800^{\circ} \mathrm{C}$.

The quantity of SiNWs obtained was accurately determined by measuring the mass of the sample using a 


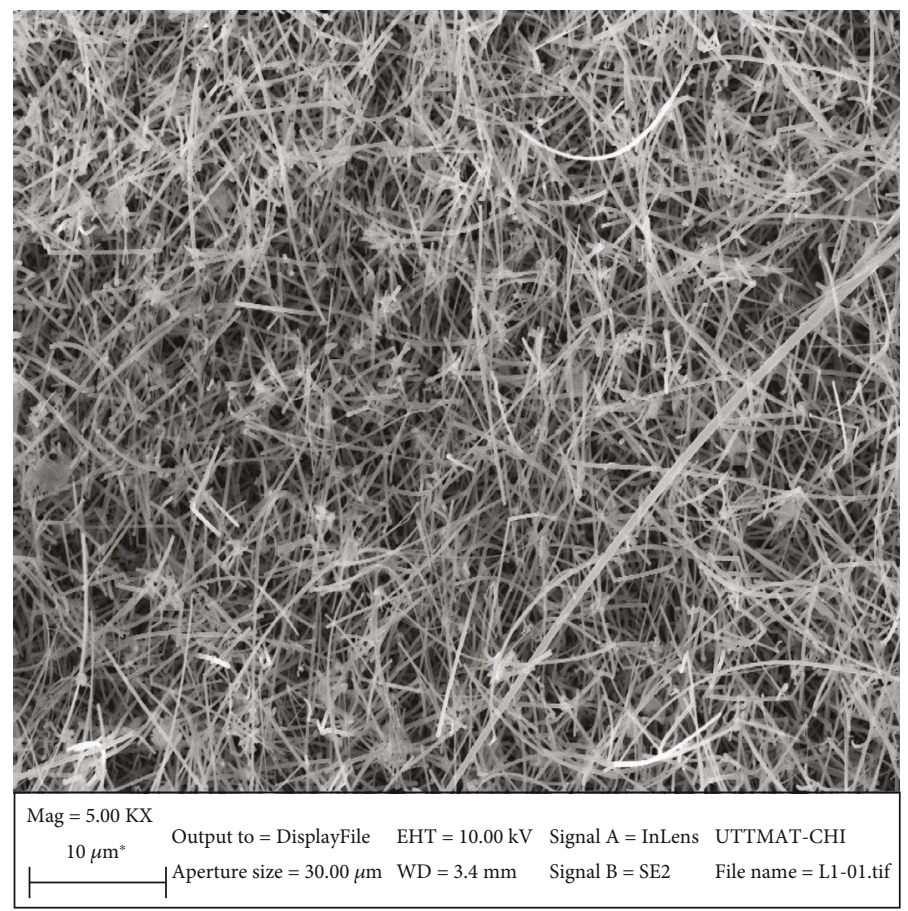

(a)

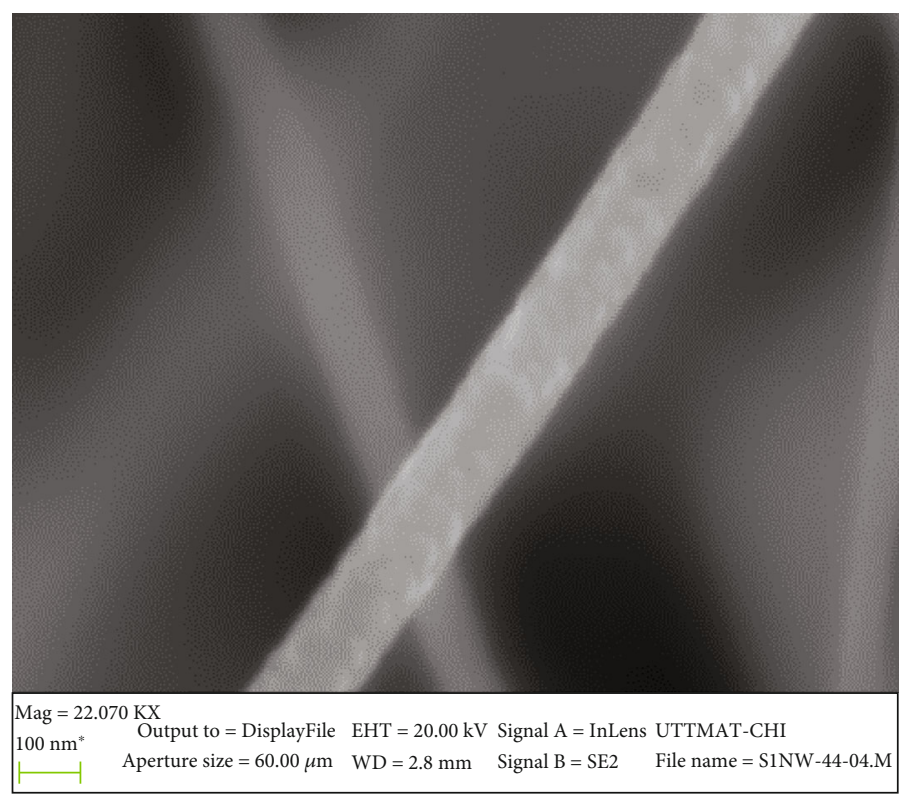

(b)

FIgure 1: (a) Low- and (b) high-magnification SEM images of SiNWs.

microbalance (Radwag 60/220/X) before and after the growth. The mass loading of the prepared SiNWs was about $1.2 \mathrm{mg} / \mathrm{cm}^{2}$, and this result is consistent with the literature for $\mathrm{Cu}$-catalysed SiNWs grown on stainless steel [45].

2.2. Morphological Characterization. The morphology of the samples was evaluated by Scanning Electron Microscopy (SEM, HR-FEGSEM LEO 1525) and Transmission Electron Microscopy (TEM, JEOL JEM2010). When the growth temperature was set to values above $700^{\circ} \mathrm{C}$, the SEM images clearly showed the absence of SiNW and the presence of a layer of silicon covering the entire surface of the stainless steel. In fact, at these temperatures, a segregation process that occurs on the stainless-steel surface and is able to modify the roughness and surface composition hinders the VLS mechanism preventing the growth of SiNW. To avoid the segregation and favour the SiNW growth, the temperature must be lowered to about $600^{\circ} \mathrm{C}$. As a result, a remarkable growth of SiNWs uniformly distributed on the steel substrate is obtained. SEM images in Figure 1 show the morphology of 
the so-obtained SiNWs. SiNWs have a length of several microns (Figure 1(a)) and a diameter of about $300 \mathrm{~nm}$ (Figure 1(b)).

In order to evaluate the SiNW structure, TEM analysis was performed. The TEM image and the diffraction pattern of Figure 2 show a core-shell crystalline-amorphous structure with the presence of a crystalline silicon (c-Si) core having the same dimension of the copper nanoparticles used as a catalyst $(40 \mathrm{~nm})$ and an amorphous silicon (a-Si) shell, formed by the pyrolytic decomposition of silane on the crystalline core. The thickness of the a-Si directly depends on the growth time and the length of the SiNWs. This double morphological character of the SiNWs is crucial for the electrochemical performance of the cell. In principle, it should be possible to use only the a-Si for $\mathrm{Li}^{+}$ion storage employing the $\mathrm{c}-\mathrm{Si}$ as an efficient electrical conducting pathway and stable mechanical support [39]. In this way, it is possible to improve the performance of the SiNW film when used as an electrode in LIBs.

2.3. Electrochemical Characterization. The SiNWs deposited on the stainless-steel substrate were directly used for the electrochemical characterization. The samples were inserted in a two-electrode cell formed by a polypropylene T-type pipe connector closed at the ends with two cylindrical stainless steel (SS316) acting as current collectors. A glass fiber (Whatman 1820-240, grade GF/A) was used as the separator. The cell was filled with ethylene carbonate/dimethyl carbonate 1:1 $\mathrm{LiPF}_{6} 1 \mathrm{M}$ electrolyte solution (LP30, Merck, battery grade). The cycling tests were carried out automatically by means of a battery cycler (MACCOR 4000). To assess the electrochemical performance, the electrodes were galvanostatically cycled between $2.0 \mathrm{~V}$ and $0.005 \mathrm{~V}$ vs. $\mathrm{Li} / \mathrm{Li}^{+}$. Cell assembly, test, and storage were performed in a dry room (R.H. $<0.1 \%$ at $20^{\circ} \mathrm{C}$ ).

\section{Results and Discussion}

In order to investigate the structural transition inside the SiNWs and understand the role of SiNW morphology on the electrochemical properties, the first and second charge/discharge voltage profiles are compared with a more accurate analysis of the differential capacity $\mathrm{dQ} / \mathrm{dV}\left(\mathrm{mAh} \mathrm{V}^{-1}\right)$ curves as shown in Figures 3(a) and 3(b) and Figures 3(c) and 3(d). The cell was cycled with a current of $0.14 \mathrm{~mA}$, corresponding to the $\mathrm{C} / 10$ rate. During the first discharge cycle, a large plateau is observed in the region below $0.15 \mathrm{~V}$ (Figure 3(a), lower curve) which corresponds to the sharp peak at $140 \mathrm{mV}$ identified by the letter $\mathrm{A}$ in the $\mathrm{dQ} / \mathrm{dV}$ curve (Figure 3(c)). In this phase, two processes are taking place: the formation of the SEI film on the surface of Si-NWs and the formation of the lithium/silicon alloy. The latter occurs in a two-phase region in which crystalline silicon is lithiated and a partial amorphous lithiated silicon is formed [9, 46, 47].

After this process has completed, a second process starts at a lower voltage, and it can be identified in the $\mathrm{dQ} / \mathrm{dV}$ curve as the sharp peak centred at around $50 \mathrm{mV}$ and identified in Figure 3 (c) by the letter $\mathrm{B}$. This process continues until the cut-off potential set at $0.05 \mathrm{~V}$ vs $\mathrm{Li}^{+} / \mathrm{Li}$ is reached. This peak

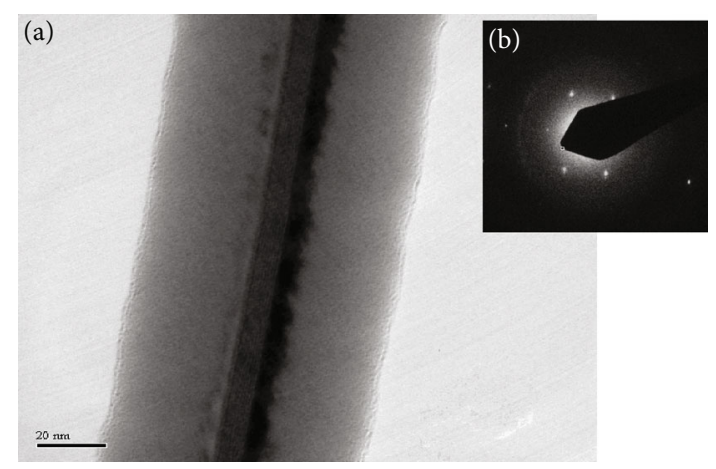

Figure 2: TEM image of Cu-catalysed SiNWs (a) and diffraction pattern (b).

can be attributed to a further lithiation step which transforms the amorphous lithiated silicon in a new crystalline $\mathrm{Li}_{15} \mathrm{Si}_{4}$ phase. At the end of the process, the capacity used for SEI film formation and Si lithiation amounts to about $2500 \mathrm{mAh} / \mathrm{g}$. In the following charge curve (Figure 3(a), upper curve), it is evident that only part of the capacity $(1800 \mathrm{mAh} / \mathrm{g})$ is reversibly extracted from the electrode. The corresponding dQ/dV curve (Figure 3(c)) shows two broad peaks at $360 \mathrm{mV}$ and $460 \mathrm{mV}$ (identified by the letters $\mathrm{C}$ and $\mathrm{D}$, respectively) which can be attributed to the extraction of lithium from two different delithiation degrees of amorphous lithiated silicon to form amorphous silicon.

During the second discharge cycle, an additional sloping region at about $0.3-0.2 \mathrm{~V}$ appears in the discharge curve (Figure $3(\mathrm{~b})$, lower curve). This plateau corresponds to the peak located at $230 \mathrm{mV}$ (A) in the $\mathrm{dQ} / \mathrm{dV}$ curve (Figure 3(d)) which is assigned to the lithiation process of the amorphous silicon coming from the dealloying reaction. As a result, the discharge capacity is reduced down to about $1900 \mathrm{mAh} / \mathrm{g}$. Similarly, to the first discharge curve, the second lithiation cycle also shows a sharp peak ( $B$ in Figure 3(d)) at a voltage below $50 \mathrm{mV}$ attributed to a further lithiation able to transform the amorphous lithiated silicon in crystalline $\mathrm{Li}_{15} \mathrm{Si}_{4}$. The voltage profile in the second charge cycle appears similar to the profile exhibited during the first cycle with the capacity maintaining a stable value of about $1800 \mathrm{mAh} / \mathrm{g}$ (Figure 3(b), upper curve). This investigation has permitted to better understand the role of the crystalline-amorphous core-shell structure of the SiNWs on the charge and discharge processes. In particular, as described above, while the reversible process can be attributed to the lithiation of crystalline $\mathrm{Si}$, the high irreversible capacity $(70 \%)$ found in the first cycle can be ascribed to the formation of a SEI passivation layer on the silicon nanowire surface, induced by the reduction of the electrolyte [48, 49]. Some authors showed that a carbon coating or a conductive polymer used as a binder can drastically reduce this irreversible loss [36, 37].

In Figure 4, the discharge/charge capacity versus cycle number for the SiNW electrode together with the charge efficiency (CE) is shown. The CE is defined as the ratio between the capacity inserted into the electrode in charge and the capacity released in the previous discharge cycle $\left(Q_{\mathrm{ch}} / Q_{\mathrm{dis}}\right)$. 


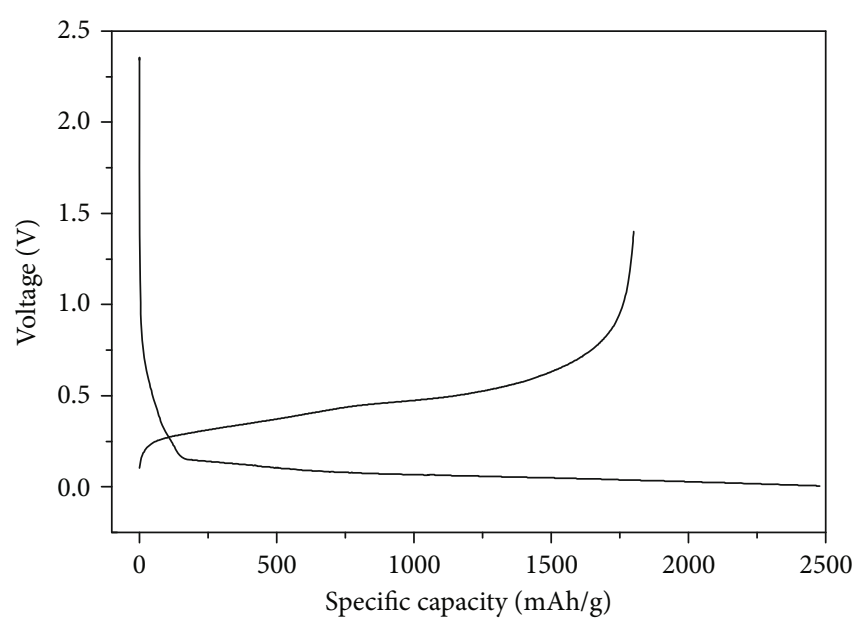

(a)

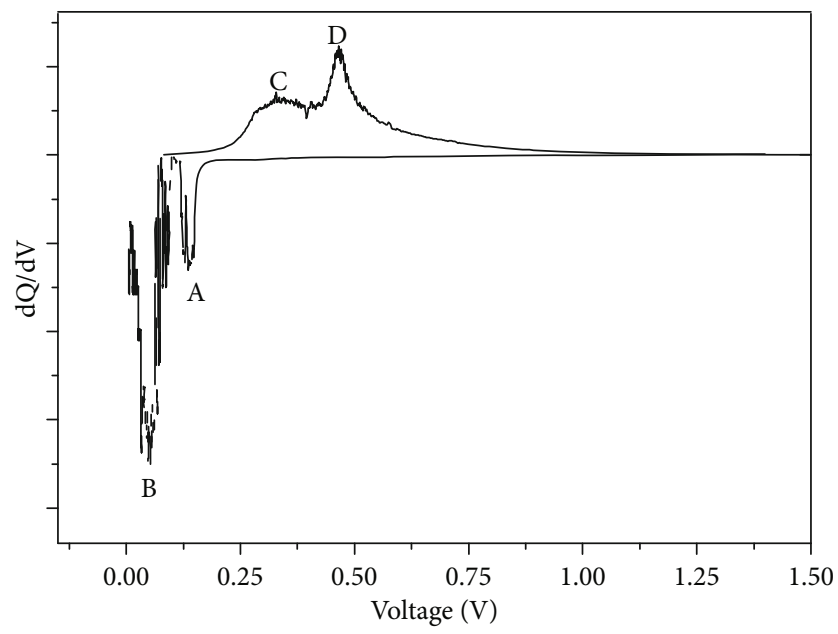

(c)

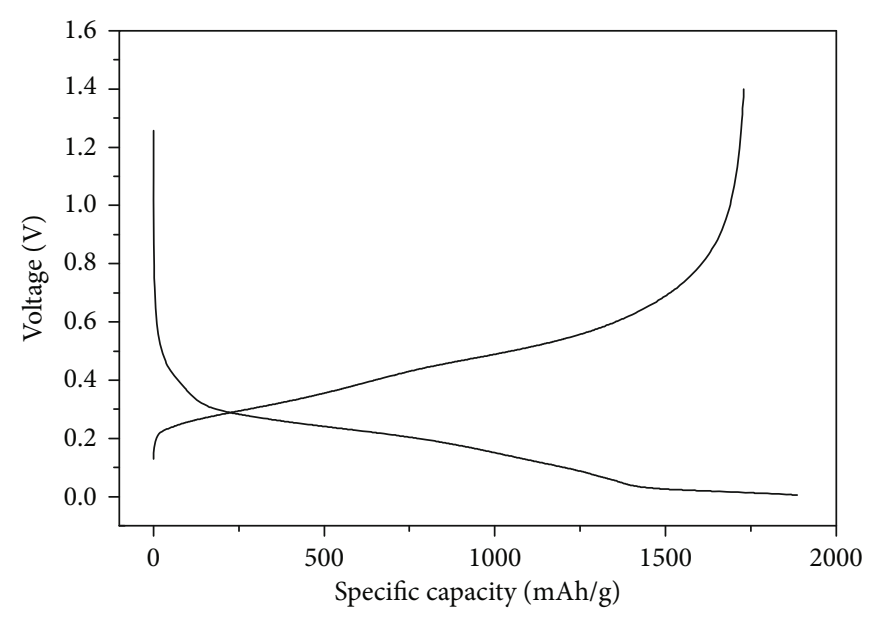

(b)

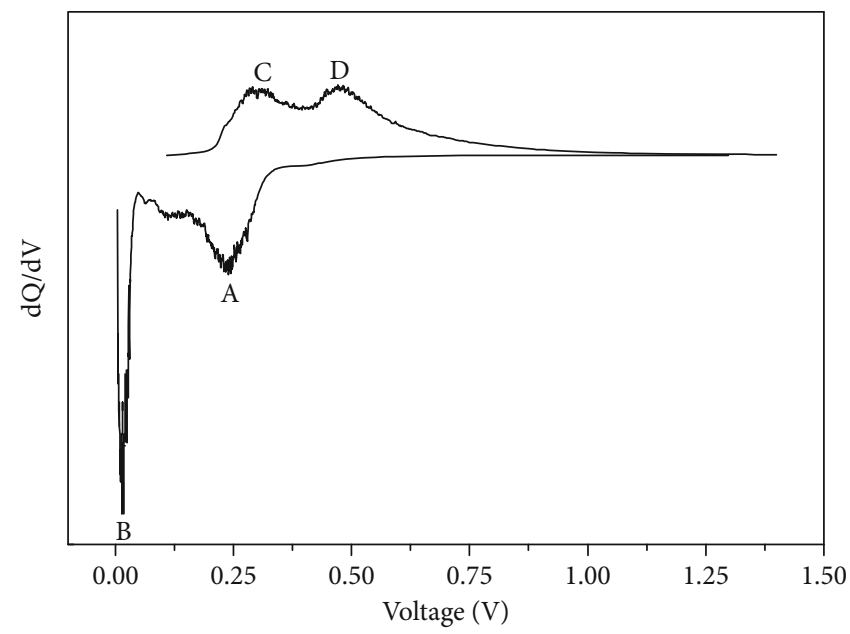

(d)

FIgURe 3: Voltage profiles as a function of capacity for the SiNWs cycled in a lithium cell at C/10 rate during the first (a) and the second (b) cycle and differential dQ/dV vs. $V$ curves corresponding to the first (c) and the second (d) cycle.

The first test was conducted at a very low charge-discharge current $(\mathrm{C} / 10$ rate) and included a limited number of cycles ( 14 cycles). However, the limited number of cycles was enough to evaluate the goodness of the SiNWs when used as anodes in LIBs. In fact, SiNWs with inappropriate morphologies exhibit poor cycling just after few cycles due to the degradation of the $\mathrm{Si}$ structure occurring during the lithiation and delithiation processes $[8,14,37]$. In our case, all cycles show a discharge capacity (circles) larger than the charge capacity (squares). After the first cycle, the CE increases up to $95 \%$, and this value was kept constant in the subsequent cycles, suggesting that no drastic change of the core-shell SiNW structure occurs and that the SiNWs remain well connected with the stainless-steel current collector. To evaluate the rate capability of the SiNWs, the cell was cycled at various charge rates. The discharge was always carried out galvanostatically at $0.2 \mathrm{~mA}(\mathrm{C} / 10$ rate), and Figure 5 shows the correspondent voltage profiles. At the lowest charge current value $(\mathrm{C} / 10$ rate), the cell exhibits a specific capacity approaching $2000 \mathrm{mAh} / \mathrm{g}$. Slightly lower values were observed when the charging current was increased from
$\mathrm{C} / 10$ to the $1 \mathrm{C}$ rate. When the current is increased to $2 \mathrm{C}$, the capacity drops down to $1600 \mathrm{mAh} / \mathrm{g}$. Another notable decrease in capacity is observed when charging the cell at $3 \mathrm{C}$ and $5 \mathrm{C}$. At the $5 \mathrm{C}$ rate, the specific capacity goes down to $1200 \mathrm{mAh} / \mathrm{g}$. From this result, it is possible to state that the SiNWs show good capacity retention with increasing charging rates, being able to provide $60 \%$ of the capacity exhibited at low current when discharged with a current 50 times higher. Therefore, our SiNW electrodes show good areal capacities also at fast charge/discharge rates (e.g., from $2.4 \mathrm{mAh} \mathrm{cm}^{-2}$ at 1C to $1.4 \mathrm{mAh} \mathrm{cm}^{-2}$ at $5 \mathrm{C}$ ) although they have low material loading of $1.2 \mathrm{mg} \mathrm{cm}^{-2}$.

Quantifying the rate performance of the SiNWs is possible by the use of a parameter as proposed by Prosini [50] and Fongy et al. [51]. They suggested the use of a parameter $\mathrm{k}$ (in hours) to characterize the system response in power. The $k$ parameter is defined by $Q=Q_{0}+k I_{m}$, where $Q$ is the charge capacity at the charge current $I_{m}$ and $Q_{0}$ is the (pseudo) equilibrium charge capacity $(\mathrm{mAh})$, i.e., the capacity evaluated at the lower charge rate. The higher is the $k$ parameter, the worse is the electrode performance in terms of power. 


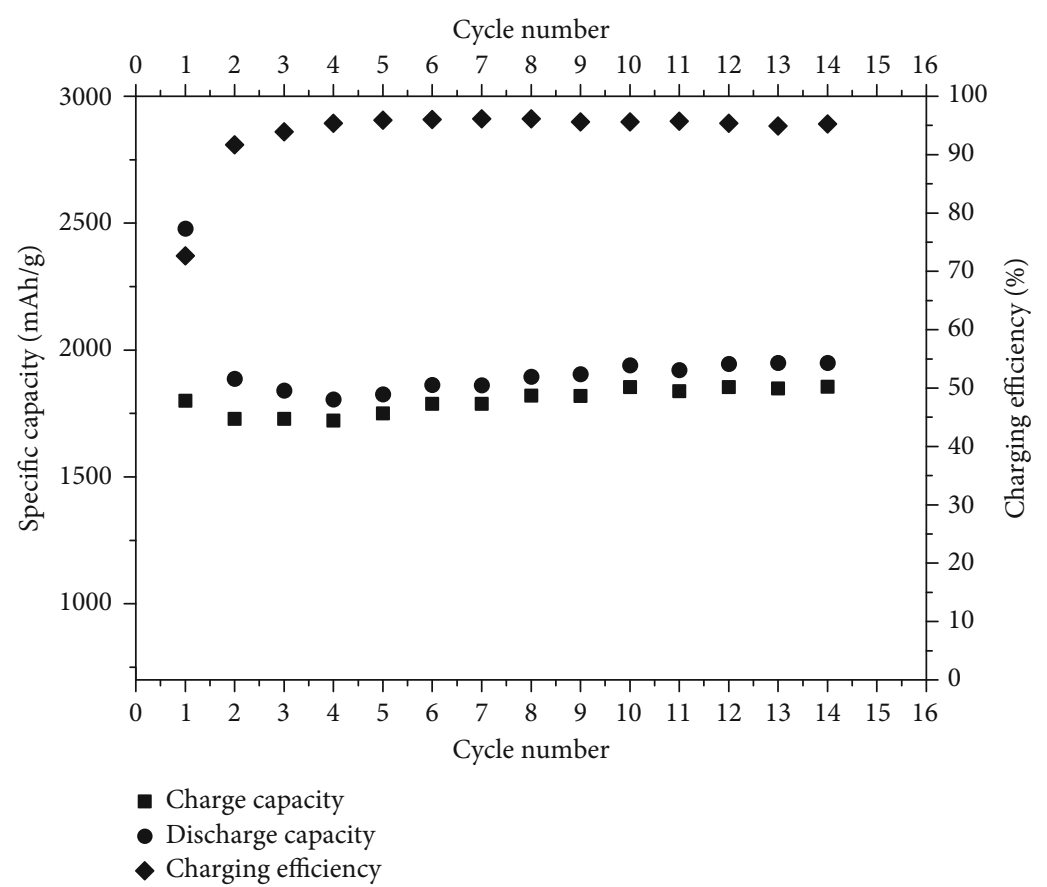

FIGURE 4: Capacity in charge and discharge and charging efficiency during the first cycles conducted at the C/10 rate.

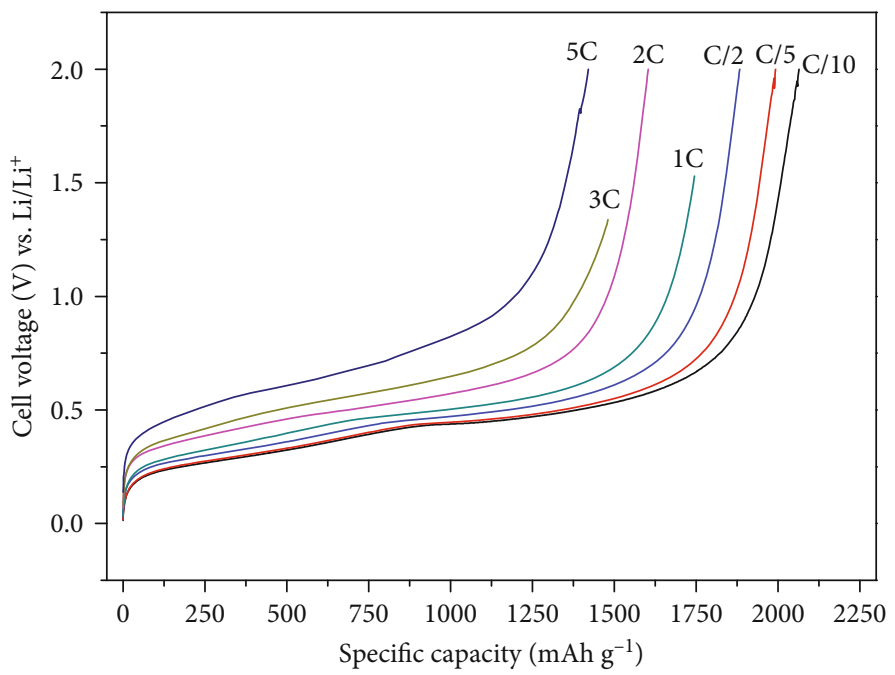

Figure 5: Charge capacity during seven cycles conducted at various charge rates. The C-rate values are reported in the figure.

Figure 6 shows the dependence of the capacity as a function of the charge current for the SiNW electrode. In our case, a linear behaviour is observed, and it is possible to evaluate the $k$ value. From the slope of the regression line, the $k$ value was calculated to be $-0.095 \mathrm{~h}$. This value is very low especially when compared to other active materials used in lithium-ion technology confirming the high rate capability of $\mathrm{Cu}-$ catalysed SiNWs $[50,51]$.

The cycling of the electrode at various charge rates was prolonged to evaluate the stability of the SiNWs as a function of the cycle number, and Figure 7 reports the values of the capacity at various $\mathrm{C}$ rates vs. cycle numbers. Contrary to what was observed during the cycles conducted at the $\mathrm{C} / 10$ rate, a severe capacity fading was observed for all the dis- charge currents. To explain this behaviour, we hypothesized that at higher rates, the current distribution is uneven, and part of the silicon nanowire grows faster than the other parts. The greater expansion of these parts causes the breakdown of the SEI film and the detachment of silicon microparticles from the nanowires. These parts become electrochemically inactive, hindering the complete lithiation of silicon nanowires in subsequent cycles. Bloom et al. [52] demonstrated that the degradation of the power capability during cycling of a Li-ion cell can be related to the increase of the cell internal resistance which can also be related to the properties of the SEI. Therefore, when nanostructured silicon electrodes are cycled at very high current rates, fresh surface areas are produced by the silicon expansion during the lithiation, as 


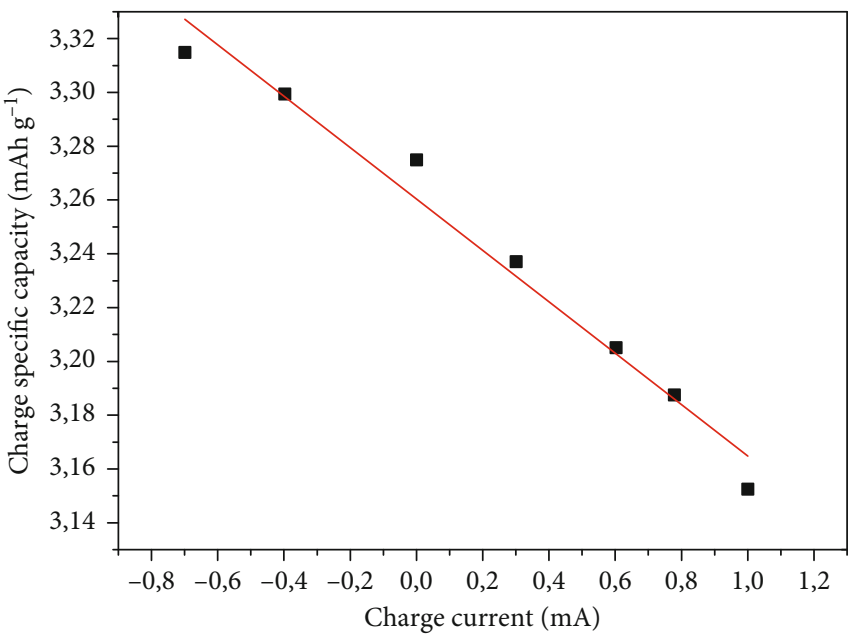

FIGURE 6: Effective capacity in charge as a function of the charge current.

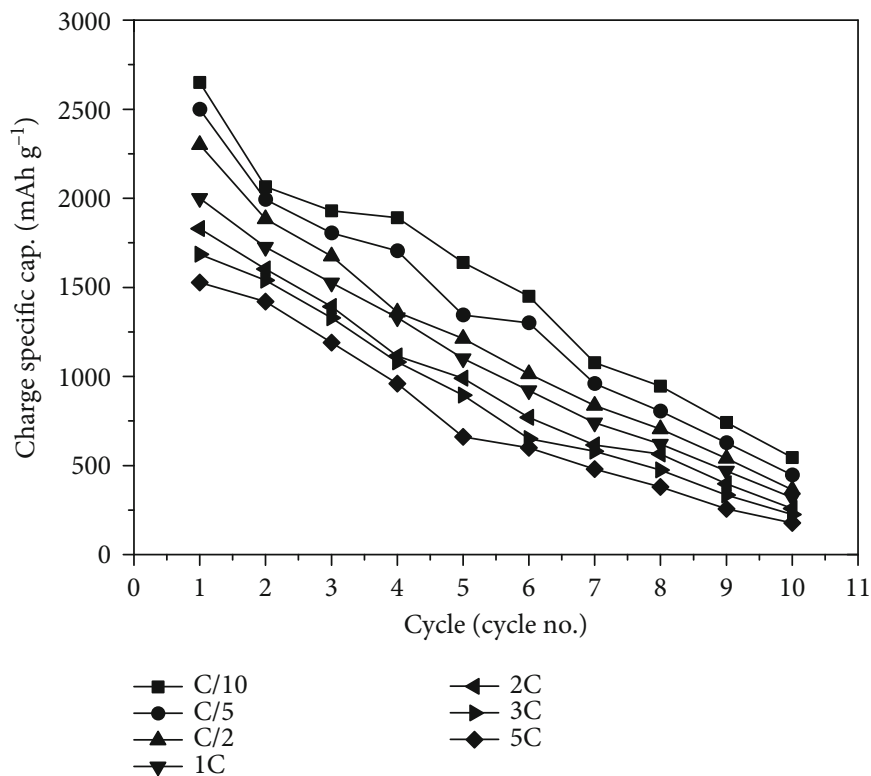

Figure 7: Capacity during charge as a function of the cycle number for the SiNW electrode cycled at various charge rates.

well described by the extension of Pinson's model shown in ref. [53]. According to this model, the linear capacity fade observed during the lithiation/delithiation processes of the cell can be attributed to the SEI formation on freshly exposed surfaces [31,32]. This result confirms the crucial role of the SEI formation on the capacity fading and cycle life of the cell.

\section{Conclusions}

In conclusion, SiNWs were grown directly on a stainless-steel substrate by $\mathrm{Cu}$ nanoparticle-catalysed CVD. SEM images show that the so-obtained SiNWs have a length of several microns and diameter ranging from $200 \mathrm{~nm}$ to $500 \mathrm{~nm}$. TEM images confirm the core-shell structure of the SiNWs with the presence of a crystalline silicon core of around $40 \mathrm{~nm}$ (the same dimension of the copper nanoparticles) and an amorphous silicon shell.
The electrochemical properties of the silicon electrode have been investigated using lithium foil as the counter and reference electrode. The high irreversible capacity observed mainly in the first cycle was attributed to the formation of the SEI layer on the silicon surface, while the other cycles have shown good capacity retention with a high charge efficiency above $90 \%$. This result confirms the good electrical contact existing between the SiNWs and the stainless-steel current collector. When compared with other active materials used in lithium-ion technology, the SiNWs exhibited a high rate capability, being able to provide $60 \%$ of the capacity exhibited at the C/10 rate when discharged with a 50 times higher current. The SiNW electrodes showed rapid capacity fade during the lithiation/delithiation processes probably attributed to the SEI formation on freshly exposed surfaces. Further investigations on the mechanism of the SEI growth can help to limit this fading, improving 
the performance of the cell in terms of capacity retention and long cycle life.

\section{Data Availability}

All data used in this article are available from the corresponding author upon request.

\section{Conflicts of Interest}

The authors declare that they have no conflicts of interest.

\section{Acknowledgments}

Part of this work was carried out within the framework "Ricerca di Sistema Elettrico" funded by the Italian Ministry of Economic Development.

\section{References}

[1] B. Scrosati and J. Garche, "Lithium batteries: status, prospects and future," Journal of Power Sources, vol. 195, no. 9, pp. 24192430, 2010.

[2] D. Linden and T. Reddy, Handbook of Batteries, Mc GrawHill, New York, 2002.

[3] C. J. Wen and R. A. Huggins, "Chemical diffusion in intermediate phases in the lithium-silicon system," Journal of Solid State Chemistry, vol. 37, no. 3, pp. 271-278, 1981.

[4] J. R. Szczech and S. Jin, "Nanostructured silicon for high capacity lithium battery anodes," Energy \& Environmental Science, vol. 4, no. 1, pp. 56-72, 2011.

[5] H. Wu and Y. Cui, "Designing nanostructured Si anodes for high energy lithium ion batteries," Nano Day, vol. 7, no. 5, pp. 414-429, 2012.

[6] M. Raić, L. Mikac, I. Marić et al., "Nanostructured silicon as potential anode material for Li-ion batteries," Molecules, vol. 25, no. 4, pp. 891-908, 2020.

[7] S. Y. Lai, K. D. Knudsen, B. T. Sejersted, A. Ulvestad, J. P. Mæhlen, and A. Y. Koposov, "Silicon nanoparticle ensembles for lithium-ion batteries elucidated by small-angle neutron scattering," ACS Applied Energy Materials, vol. 2, no. 5, pp. 3220-3227, 2019.

[8] C. K. Chan, H. Peng, G. Liu et al., "High-performance lithium battery anodes using silicon nanowires," Nature Nanotechnology, vol. 3, no. 1, pp. 31-35, 2008.

[9] Y. Yang, W. Yuan, W. Kang et al., "A review on silicon nanowire-based anodes for next-generation highperformance lithium-ion batteries from a material-based perspective," Sustainable Energy \& Fuels, vol. 4, no. 4, pp. 15771594, 2020.

[10] M. H. Park, M. G. Kim, J. Joo et al., "Silicon nanotube battery anodes," Nano Letters, vol. 9, no. 11, pp. 3844-3847, 2009.

[11] J. Tang, Q. Yin, Q. Wang et al., "Two-dimensional porous silicon nanosheets as anode materials for high performance lithium-ion batteries," Nanoscale, vol. 11, no. 22, pp. 1098410991, 2019.

[12] H. Wang, W. Tang, L. Ni et al., "Synthesis of silicon nanosheets from kaolinite as a high-performance anode material for lithium-ion batteries," Journal of Physics and Chemistry of Solids, vol. 137, p. 109227, 2020.
[13] S.-W. Park, J. H. Ha, J. M. Park, B. W. Cho, and H.-J. Choi, "2D silicon nanosheets/carbon composites based foldable anode electrode for lithium-ion batteries," Journal of The Electrochemical Society, vol. 167, no. 2, article 020556, 2020.

[14] N. Bensalah, F. Z. Kamand, M. Zaghou, H. D. Dawoud, and T. Al Tahtamouni, "Silicon nanofilms as anode materials for flexible lithium ion batteries," Thin Solid Films, vol. 690, p. 137516, 2019.

[15] T. Ikonen, T. Nissinen, E. Pohjalainen, O. Sorsa, T. Kallio, and V.-P. Lehto, "Electrochemically anodized porous silicon: towards simple and affordable anode material for Li-ion batteries," Nature, vol. 7, no. 1, article 7880, 2017.

[16] W. Wang, Z. Favors, R. Ionescu et al., "Monodisperse Porous Silicon Spheres as Anode Materials for Lithium Ion Batteries," Nature, vol. 5, no. 1, p. 8781, 2015.

[17] H. F. Andersen, C. E. L. Foss, J. Voje et al., "Silicon-carbon composite anodes from industrial battery grade silicon," Scientific Reports, vol. 9, no. 1, article 14814, 2019.

[18] S. Chae, S. H. Choi, N. Kim, J. Sung, and J. Cho, "Integration of graphite and silicon anodes for the commercialization of highenergy lithium-ion batteries," Angewandte Chemie, International Edition, vol. 59, no. 1, pp. 110-135, 2020.

[19] G. Fang, X. Deng, J. Zou, and X. Zeng, “Amorphous/ordered dual carbon coated silicon nanoparticles as anode to enhance cycle performance in lithium ion batteries," Electrochimica Acta, vol. 295, pp. 498-506, 2019.

[20] M. Phadatare, R. Patil, N. Blomquist et al., "Silicon-nanographite aerogel-based anodes for high performance lithium ion batteries," Scientific Reports, vol. 9, no. 1, article 14621, 2019.

[21] W. Wang, R. Epur, and P. N. Kumta, "Vertically aligned silicon/carbon nanotube (VASCNT) arrays: hierarchical anodes for lithium-ion battery," Electrochemistry Communications, vol. 13, no. 5, pp. 429-432, 2011.

[22] Y. Li, K. Yan, H.-W. Lee, Z. Lu, N. Liu, and Y. Cui, "Growth of conformal graphene cages on micrometre-sized silicon particles as stable battery anodes," Nature Energy, vol. 1, no. 2, article 15029, 2016.

[23] M. S. Wang, Z. Q. Wang, R. Jia et al., "Facile electrostatic selfassembly of silicon/reduced graphene oxide porous composite by silica assist as high performance anode for Li-ion battery," Applied Surface Science, vol. 456, pp. 379-389, 2018.

[24] S. Yoo, J.-I. Lee, S. Ko, and S. Park, "Highly dispersive and electrically conductive silver-coated $\mathrm{Si}$ anodes synthesized via a simple chemical reduction process," Nano Energy, vol. 2, no. 6, pp. 1271-1278, 2013.

[25] Z. Chen and Z. Xie, "First-principles investigation on cluster-assembled silicon nanotubes with Eu atoms encapsulation," Journal of Molecular Modeling, vol. 25, no. 8, p. 226, 2019.

[26] M. Feng, J. Tian, H. Xie, Y. Kang, and Z. Shan, "Nano-silicon/polyaniline composites with an enhanced reversible capacity as anode materials for lithium ion batteries," Journal of Solid State Electrochemistry, vol. 19, p. 2015, 2015.

[27] C. Gan, C. Zhang, P. Liu et al., "Polymeric carbon encapsulated $\mathrm{Si}$ nanoparticles from waste $\mathrm{Si}$ as a battery anode with enhanced electrochemical properties," Electrochimica Acta, vol. 307, pp. 107-117, 2019.

[28] G. G. Eshetu and E. Figgemeier, "Confronting the challenges of next-generation silicon anode-based lithium-ion batteries: role of designer electrolyte additives and polymeric binders," ChemSusChem, vol. 12, no. 12, pp. 2515-2539, 2019. 
[29] M. R. Zamfir, H. T. Nguyen, E. Moyen, Y. H. Lee, and D. Pribat, "Silicon nanowires for Li-based battery anodes: a review," Journal of Materials Chemistry A, vol. 1, no. 34, pp. 9566-9586, 2013.

[30] A. Wang, S. Kadam, H. Li, S. Shi, and Y. Qi, "Review on modeling of the anode solid electrolyte interphase (SEI) for lithiumion batteries," npj Computational Materials, vol. 4, no. 1, 2018.

[31] A. L. Michan, G. Divitini, A. J. Pell, M. Leskes, C. Ducati, and C. P. Grey, "Solid electrolyte interphase growth and capacity loss in silicon electrodes," Journal of the American Chemical Society, vol. 138, no. 25, pp. 7918-7931, 2016.

[32] E. Peled, D. B. Tow, A. Merson, A. Gladkich, L. Burstein, and D. Golodnitsky, "Composition, depth profiles and lateral distribution of materials in the SEI built on HOPG-TOF SIMS and XPS studies," Journal of Power Sources, vol. 97-98, pp. 52-57, 2001.

[33] M. F. Hainey and J. M. Redwing, "Aluminum-catalyzed silicon nanowires: growth methods, properties, and applications," Applied Physics Reviews, vol. 3, no. 4, article 040806, 2016.

[34] M. Sadeghipari, A. Mashayekhi, and S. Mohajerzadeh, "Novel approach for improving the performance of Si-based anodes in lithium-ion batteries," Nanotechnology, vol. 29, article 055403, 2018.

[35] L. F. Cui, Y. Yang, C. M. Hsu, and Y. Cui, "Carbon-silicon core-shell nanowires as high capacity electrode for lithium ion batteries," Nano Letters, vol. 9, no. 9, pp. 3370-3374, 2009.

[36] T. D. Bogart, D. Oka, X. Lu, M. Gu, C. Wang, and B. A. Korgel, "Lithium ion battery Peformance of silicon nanowires with carbon skin," ACS Nano, vol. 8, no. 1, pp. 915-922, 2013.

[37] A. M. Chockla, T. D. Bogart, C. M. Hessel, K. C. Klavetter, C. B. Mullins, and B. A. Korgel, "Influences of gold, binder and electrolyte on silicon nanowire performance in Li-ion batteries," The Journal of Physical Chemistry C, vol. 116, no. 34, pp. 18079-18086, 2012.

[38] P. P. Prosini, C. Cento, A. Rufoloni, F. Rondino, and A. Santoni, "A lithium-ion battery based on $\mathrm{LiFePO}_{4}$ and silicon nanowires," Solid State Ionics, vol. 269, pp. 93-97, 2015.

[39] L.-F. Cui, R. Ruffo, C. K. Chan, H. Peng, and Y. Cui, "Crystalline-amorphous core-shell silicon nanowires for high capacity and high current battery electrodes," Nano Letters, vol. 9, no. 1, pp. 491-495, 2009.

[40] R. S. Wagner and W. C. Ellis, "Vapor-liquid-solid mechanism of single crystal growth," Applied Physics Letters, vol. 4, no. 5, pp. 89-90, 1964.

[41] E. I. Givargizov, "Fundamental aspects of VLS growth," Journal of Crystal Growth, vol. 31, pp. 20-30, 1975.

[42] Y. Yao and S. Fan, "Si nanowires synthesized with Cu catalyst," Materials Letters, vol. 61, no. 1, pp. 177-181, 2007.

[43] J. Arbiol, B. Kalache, P. R. i. Cabarrocas, J. R. Morante, and A. F. i. Morral, "Influence of $\mathrm{Cu}$ as a catalyst on the properties of silicon nanowires synthesized by the vapour-solid-solid mechanism," Nanotechnology, vol. 18, no. 30, article 305606, 2007.

[44] J. L. Lensch-Falk, E. R. Hemesath, D. E. Perea, and L. J. Lauhon, "Alternative catalysts for VSS growth of silicon and germanium nanowires," Journal of Materials Chemistry, vol. 19, no. 7, pp. 849-857, 2009.

[45] Y. Xiao, D. Hao, H. Chen, Z. Gong, and Y. Yang, "Economical synthesis and promotion of the electrochemical performance of silicon nanowires as anode material in Li-ion batteries,"
Applied Materials \& Interfaces, vol. 5, no. 5, pp. 1681-1687, 2013.

[46] A. L. Michan, M. Leskes, and C. P. Grey, "Voltage dependent solid electrolyte interphase formation in silicon electrodes: monitoring the formation of organic decomposition products," Chemistry of Materials, vol. 28, no. 1, pp. 385-398, 2016.

[47] M. N. Obrovac and L. Christensen, "Structural changes in silicon anodes during lithium insertion/extraction," Electrochemical and Solid-State Letters, vol. 7, no. 5, pp. A93-A96, 2004.

[48] J. H. Cho and S. T. Picraux, "Silicon nanowire degradation and stabilization during lithium cycling by SEI layer formation," Nano Letters, vol. 14, no. 6, pp. 3088-3095, 2014.

[49] G. Lee, S. L. Schweizer, and R. B. Wehrspohn, "Microstructural characterization of $\mathrm{Li}$ insertion in individual silicon nanowires," Applied Physics A: Materials Science \& Processing, vol. 117, no. 3, pp. 973-979, 2014.

[50] P. P. Prosini, "Modeling the voltage profile for LiFePO[sub 4]," Journal of the Electrochemical Society, vol. 152, no. 10, pp. A1925-A1929, 2005.

[51] C. Fongy, A. C. Gaillot, S. Jouanneau, D. Guyomard, and B. Lestriez, "Ionic vs electronic power limitations and analysis of the fraction of wired grains in $\mathrm{LiFePO}$ [sub 4] composite electrodes," Journal of the Electrochemical Society, vol. 157, no. 7, pp. A885-A891, 2010.

[52] I. Bloom, B. W. Cole, J. J. Sohn et al., "An accelerated calendar and cycle life study of Li-ion cells," Journal of Power Sources, vol. 101, no. 2, pp. 238-247, 2001.

[53] M. B. Pinson and M. Z. Bazant, "Theory of SEI formation in rechargeable batteries: capacity fade, accelerated 356 aging and lifetime prediction," Journal of the Electrochemical Society, vol. 160, pp. A243-A250, 2012. 